\title{
Cartografía social. Los simulacros culturales en el chat.
}

\section{Social cartography. Cultural drills in chat.}

\author{
Giselda Hernández Ramírez, \\ Universidad de las Artes de Cuba. \\ giseldah41@gmail.com
}

Recibido: 19/12/2020 Revisado: 29/12/2020

Aceptado: 03/12/2021 Publicado: 14/01/2021

\section{Resumen}

Este foto ensayo sintetiza una cartografía social realizada en la Universidad de las Artes de Cuba a partir de la creación de grupos de chat en la Facultad de Arte danzario en el mes de marzo del (2020) como alternativa para impartir docencia ante la situación de confinamiento que se vive en el mundo, en el mismo se analizan los simulacros culturales generados por la propia dinámica de los grupos, se exponen los acuerdos efímeros, capacidad de representación, entrecruzamientos de planos mentales y conductuales en el chat con una noción performativa, así como, los ejercicios de poder para en alguna medida develar las cotidianidades de los grupos creados y su contenido de valor simbólico y criterios de distinción.

\section{Sugerencias para citar este artículo:}

Hernández Ramírez, Giselda (2021). Cartografía social. Los simulacros culturales en el chat. Tercio Creciente 19, (pp. 85-109), https://dx.doi.org/10.17561/rtc.19.6230

HERNÁNDEZ RAMÍREZ, GISELDA. Cartografía social. Los simulacros culturales en el chat. Tercio Creciente, enero 2021, pp. 85-109, https://dx.doi.org/10.17561/rtc.19.6230 
DOI: https://dx.doi.org/10.17561/rtc.19.6230 Investigación
La cuestión imaginativa: del dibujo y la fotografía a la imagen en movimento

Enero 2021

\section{Abstract}

This photo essay synthesizes a social cartography carried out at the University of the Arts of Cuba from the creation of chat groups at the Faculty of Dance Art in March (2020) as an alternative to teach in the face of the situation of confinement that is lived in the world, in it the cultural simulations generated by the dynamics of the groups are analyzed, the ephemeral agreements, capacity for representation, interlocking of mental and behavioral planes are exposed in the chat with a performative notion, as well as, the exercises of power to some extent to reveal the daily life of the created groups and their content of symbolic value and criteria of distinction.

\section{Palabras Clave / Key Words}

Simulacros culturales, representación, valor simbólico, poder.

Cultural simulations, representation, symbolic value, power.

\section{Sugerencias para citar este artículo:}

Hernández Ramírez, Giselda (2021). Cartografía social. Los simulacros culturales en el chat. Tercio Creciente 19, (pp. 85-109), https://dx.doi.org/10.17561/rtc.19.6230

HERNÁNDEZ RAMÍREZ, GISELDA. Cartografía social. Los simulacros culturales en el chat. Tercio Creciente, enero 2021, pp. 85-109, https://dx.doi.org/10.17561/rtc.19.6230 
DOI: https://dx.doi.org/10.17561/rtc.19.6230 Investigación
La cuestión imaginativa: del dibujo y la fotografía a la imagen en movimento

Enero 2021

Había una vez... una isla, un contexto surrealista. ¡Café! ${ }^{1}$

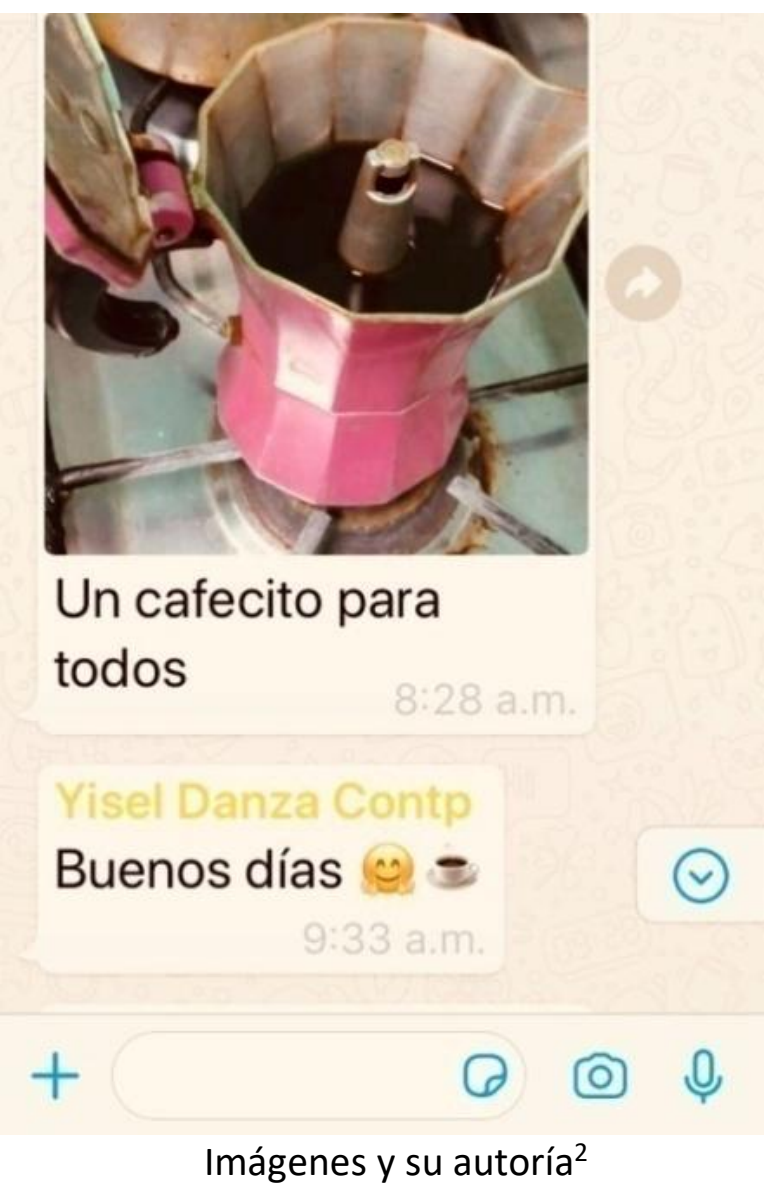

\footnotetext{
${ }^{1}$ Antes de comenzar la pandemia se produjo un desabastecimiento en las tiendas expendedoras de productos alimenticios en Cuba por causas disímiles políticas y económicas en este contexto el café se ha convertido en un producto casi inexistente y de alta demanda por la población.

2 Las imágenes de este texto son producidas por la autora, no son ilustraciones, son los elementos de la narrativa visual, del ensayo de imágenes, razón por a que carecen de pie de foto.
} 
La naturaleza de este trabajo es autoreferencial en tanto formo parte del juego de los espejos de apariencia sin perder de vista que "cuando la sociedad se refleja en el espejo de la red, de la virtualidad, ésta no pasa a ser una cibersociedad, tan sólo lo parece, pues no es el único espejo en que se mira, y, aún siéndolo, tan solo mostraría un reflejo" (Anta, J. y Palacios, J. 2003 p. 79). Nuestro gran juego cultural comenzó por el meses de febrero 2020, caracterizado en esta oportunidad por tocar a los ciudadanos del mundo, con lo cual no estábamos solos, y yo diría que la hora 0 para cubanas/nos. No sé si esta coyuntura nos llegó desfasada como casi todo, pero lo cierto es que el encierro auto e impuesto, la normalización del miedo y el destierro de la sospecha nos llegó, Venecia y sus máscaras, el carnaval, los regaños por los medios, la culpa en fin, y sin ignorar la realidad, las vidas que se ha cobrado y lo que ha implicado esta pandemia no puedo dejar de pensar en Maikel Jackson (2010)antropólogo- cuando esgrime "el confinamiento forzoso está conectado con el valor que se da al autodominio y la autocontención" p.76 y me asalta la pregunta ¿ será esto un ritual iniciático? Porque... la iniciación como proceso entre otras cuestiones cumple con la función de domesticar emociones, cuerpos indisciplinados, asimismo se plantea que estas prácticas se realizan para enderezar lo torcido, endurecer y vuela otra pregunta ¿estaremos ante un ritual de iniciación y no nos hemos enterado? Pudiera ser pero... este ensayo no va de ello con lo cual vuelvo al tema.

Para estudiantes y profesores en la Universidad de las Artes de Cuba, la fecha fue el 23 de marzo de 2020, ese día se dio un giro al proceso de enseñar- aprender ya partir de este momento se crearon grupos de chat universitarios o educación online para mantenernos en contacto académico; al tomar la alternativa de una especie de teletrabajo intermitente, este simulacro cultural se fue ampliando con la creación de varios grupos de "trabajo de WhatsApp". 
DOI: https://dx.doi.org/10.17561/rtc.19.6230 Investigación
La cuestión imaginativa: del dibujo y la fotografía a la imagen en movimento

Enero 2021

Cuba, un país en vías de desarrollo

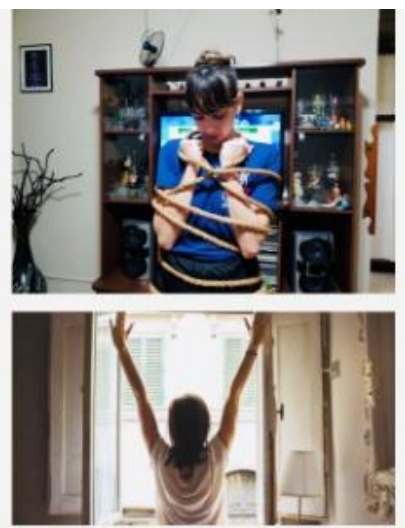

ha tratado de ponerse a tono con el avance de internet en el mundo y su gobernanza ${ }^{4}$, con muchas limitaciones y una conexión que hace galas a esa insularidad construida y reconstruida una $y$ otra vez navegamos $o$ simulamos intermitentemente navegar.

\author{
WhatsApp aprobó \\ nuevas funciones \\ para manetener en \\ contacto durante el \\ periodo de \\ CUARENTENA, por \\ motivos de seguridad \\ puedes utilizar \\ WhatsApp sin \\ necesidad de wifi o \\ datos. Tambien \\ puedes activar \\ VideoChat en grupo \\ para mantenertete en \\ linea con tu familia en
}

\footnotetext{
${ }^{3}$ Foto tomada del ensayo visual mi Cuerpo confinado de la bailarina Mónica Viqueira Camacho. Ejercicio que oriento a los bailarines y que no se corresponde con la situación pandémica pues el confinamiento corporal tiene matices muy diversos.

${ }^{4}$ Jovan Kurbalija, Laura DeNardis han elaborado diversas definiciones sobre el término gobernanza de internet que va más allá de los aspectos legales, económicos y socioculturales sino abarca aquellos regulatorios de contenidos violentos, amenazadores, actividades ilegales et al.
} 
Una inmersión sobre lecturas que tocan el tema de la gobernanza de internet me lleva a hacer un primer alto en la conceptualización de Yochai Benkler (2000) específicamente en la primera de las tres capas a las que alude, nivel de infraestructura física a través de la cual viajan los datos, inconveniente con el cual contamos los cubanos/nas, pues aun cuando la velocidad de conectividad ha mejorado con la 4G, saltan detalles importantes: a) debes poseer un teléfono que te permita acceder a esta plataforma y b) dinero para costear los datos para navegar desde tu casa, o un parque público donde se hallan ubicadas las zonas wifi, con ello jugamos a estar conectados y nos reflejamos en ese espejo de apariencia (Anta y Palacios 2003). Todo ello, coloca al sujeto poseedor de tecnología y dinero en una posición de poder con respecto a los otros, que su vez, son generadoras de relaciones positivas para algunos y negativas para otros.

El juego, los simulacros, el texto performativo.

El viaje al juego cultural de los espejos y los simulacros culturales se dirige del contexto a los contenidos generados en el chat que, durante este tiempo he estado intercambiando con cuatro grupos de las especialidades de danza contemporánea, ballet, danzología y folklore con el propósito de realizar una comprensión holística dirigida a efectuar un análisis semiótico- social al estilo derridiano y entender otras textualidades sociales (Anta, J y Palacios, J, 2003 p. 77).

Para ello el camino que elegí fue el foto ensayo o foto relato pues me permite exponer y valorar modos, modas, experiencia sociales ¿qué significaciones, qué formas de recreación identitaria y de relación se dan en el chat y cómo reflejan la realidad externa? (Anta, J y Palacios, J. 2003 p.77) eligiendo el antedicho como metáfora espacio-social que me permitió contemplar acuerdos, desacuerdos y los simulacros culturales en los contenidos elaborados en el mismo. 
DOI: https://dx.doi.org/10.17561/rtc.19.6230 Investigación
La cuestión imaginativa: del dibujo y la fotografía a la imagen en movimento

Enero 2021

Para la realización de este ensayo envié un

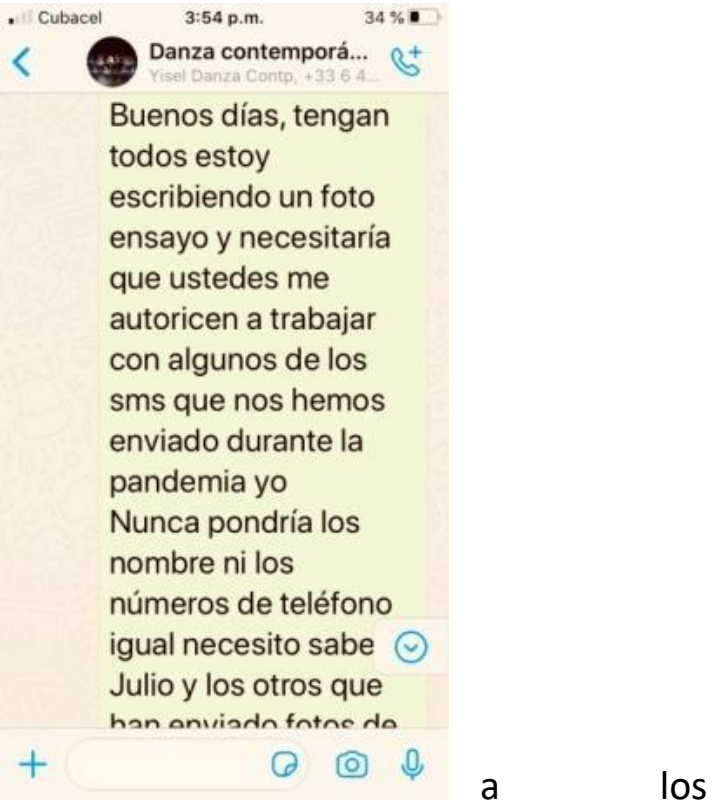
estudiantes

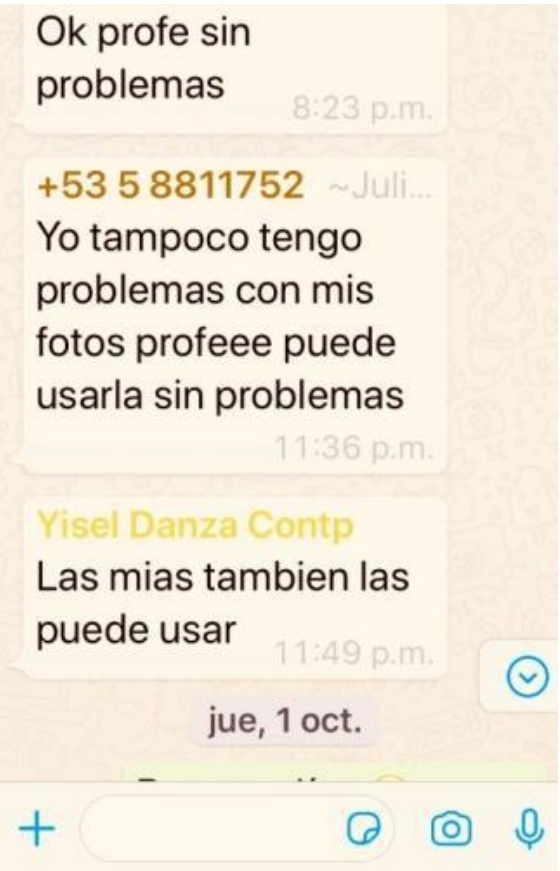

agrupados en cuatro chats y al

Dr.C Noel Bonilla Chongo jefe de carrera de la especialidad de danza contemporánea y, por consentimiento informado los contenidos generados los utilicé para crear este texto performativo. El grupo de chat de danza contemporánea se creó el 6 de febrero de 2020 y el 23 de Marzo de 2020 se desarrollaron los primero intercambios a posteriori se crearon el resto de los grupos. 
La Universidad de las Artes de Cuba como cualesquiera estructura social, cultural e institucional es un espacio en el cual se explicitan relaciones de poder creadoras y subordinadoras, constructivas y destructivas, positivas y negativas, estas relaciones que en el terreno se dan a través de grupos de poder portadores de etnocentrismos disciplinares y epistemocentrismos se robustecieron cuando comenzamos el juego de los espejos en la red, durante el proceso de aculturación antagónica que se manifiesta en la escuela por esta vez en la red, y que Wolcott, H. 2007, compara con aquella que se establece en una prisión entre los presos y sus cuidadores ante períodos largos de tiempo sin que se produzcan cambios de status.

Aquellos maestros/tras que saldamos los primeros escollos tecnológicos y económicos debíamos superar retos sobre el manejo de la tecnología pues, en la inmensa mayoría constituimos el grupo de los migrantes ante los nativos tecnológicos los estudiantes, status generador de una relación subordinadora estudiante/maestro, que desde mi perspectiva suele ser positiva, creativa, constructiva, de aprendizaje, porque contiene una sinergia de inversión de las relaciones de poder entre los grupos que no siempre se visibiliza en el contexto educativo y que en alguna medida trasvierte los antagonismos generados en el proceso de aculturación.

Sin embargo, aquellos maestros/tras y estudiantes que no pudieron mantener esta dinámica por cuestiones económicas o tecnológicas desde el punto de vista simbólico fueron exiliados, éste pudo ser un autoexilio por las condicionantes

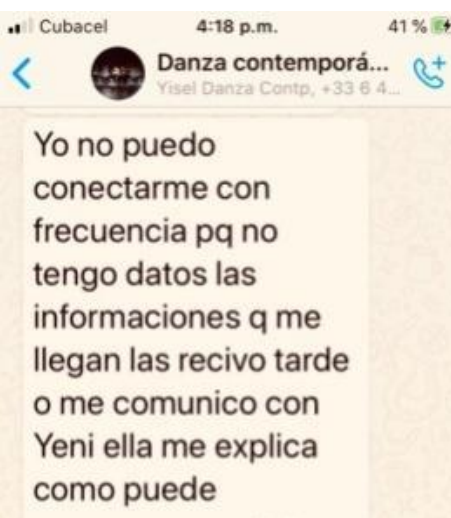

anteriormente expuestas o no,

pero lo cierto es 
que estas personas dejaron de ser visibles en este tiempo de simulacro a partir de condicionantes reales; es conocido quelos grupos en contacto virtual o real tejen imaginarios alrededor de sus miembros y en este caso la conectividad simulada acarreó relaciones negativas sobre algunas/nos, tal es el caso de $\mathbf{H}$, quien refirió imposibilidad para formar parte del chat y por consiguiente evaluarse, esta persona estableció una relación subordinadora con respecto a la tecnología y el dinero obviando las maneras tradicionales de comunicación maestro-estudiante en este archipiélago en el cual la utilización de estos medios para la docencia recién comienzan, no comportándose así J, quien se apoya en un miembro del grupo generando una red de ayuda dentro de la red que le permitiese examinarse.

Estos grupos creados establecieron desde los imaginarios sociales -a partir de las condicionantes antes esbozadas- juegos de espejos de apariencias continentes de relaciones de poder económico. Es necesario explicar que, los detentadores simbólicos de poder en nuestra sociedad se movieron desde, la tenencia de oro por los/las cubanos hasta, la tecnología; ello pudiera dar fe de la estratificación social que vive Cuba, sin embargo, no me aventuro totalmente a ello, dado los múltiples simulacros que aparecen en el telar social en el cual uno de ellos, es el de conectividad, intermitente o permanente pero que, a nivel simbólico su posesión deriva en la idea de una determinada solvencia económica. Este tejido fluye como resultante del modus vivendi de una sociedad que se me antoja encostrada culturalmente donde sus ciudadanos/nas hacemos de los juegos de espejos y simulacros nuestro día a día 5 .

Así fue como en esta comunidad virtual todos/todas vivimos nuestra construcciones culturales, sociales y psicológicas (Abdelnour, 2002, Anta, J y Palacios, J, 2003) pues en ellas se reconstruyen, reacuerdan y reinterpretan ciertas convenciones

\footnotetext{
${ }^{5}$ Todo indica que el coloniaje mental es un imperativo que nos mueve a intentar parecernos a los otros, los que viven en el primer mundo pues estos encostramientos culturales y los simulacros están ampliamente ejemplificados en obras literarias y teatrales cubanas.
} 
DOI: https://dx.doi.org/10.17561/rtc.19.6230

Investigación
La cuestión imaginativa: del dibujo y la fotografía a la imagen en movimento

Enero 2021

sociales, incluso culturales,

\section{Hola a todos aquí les dejo un interesante trabajo. Explica las formas de contagio de virus y como combatirlos. llustrado para niños y para aquellos no tan niños

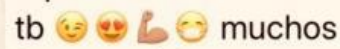 besos, cuídense. Espero vernos pronto en el salón.}

Cubacel
Danza pontemporá...
+53 58811752
Bueno les informó
que estoy en un
centro de aislamiento
en el barrio hubo una
positiva ,Pero no tuve
ningún tipo de
contacto la positiva
vice como a 6
cuadras

concreto,

medio de acuerdos momentáneos, efímeros que cada vez se renuevan y recolocan, lo cual, en cualquier caso, no es algo plenamente especifico de un chat, sino que tiene mucho que ver con un tipo de relaciones de carácter urbano (Delgado, 1999, Anta, J y

Palacios, J, 2003 p. 76) caracterizada por el simulacro cultural.

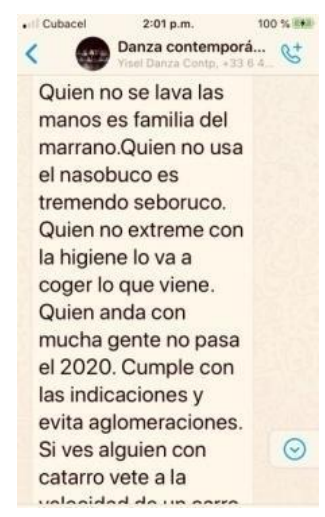


DOI: https://dx.doi.org/10.17561/rtc.19.6230 Investigación
La cuestión imaginativa: del dibujo y la fotografía a la imagen en movimento

Enero 2021

La comunicación en los chat se caracterizó por acuerdos

\author{
Danza segundo año, \\ mañana estaremos \\ con ustedes, todos \\ presentes!!! Buena \\ noche.
}

24 de mar. de 2020 Bnos días soy la profe de antropología aquí les traigo la carpeta con todos los materiales estoy en la facultad por favor necesito ver a Jesús

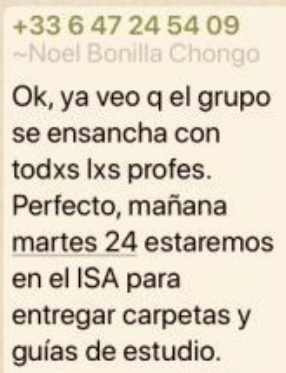

efímeros, una vez avanzada la misma se puso de evidencia en el grupo Z, que no todos/das se responsabilizaron con la recogida de la carpeta de estudio de antropología lo que conllevó a una relación de poder v/s subordinación, antagónica entre ellos/ellas y yo, los estudiantes en un acto de legítima defensa apelaron por la construcción de techos de cristal, situación observada en los chat de algunas/nos del $\mathrm{CRD}^{6}$ que manifestaban su imposibilidad para evaluarse, motivación develada como prioridad a partir de los criterios emitidos.

Ello evidenció que la construcción de conocimientos con cierta autonomía dadas las circunstancias y el proceso de aprender no constituyeron un reforzador sino, el fin que perseguían era la calificación, con lo cual enseñar y aprender sin el maestro/a

\footnotetext{
${ }^{6}$ CRD curso regular diurno.
} 
DOI: https://dx.doi.org/10.17561/rtc.19.6230 Investigación
La cuestión imaginativa: del dibujo y la fotografía a la imagen en movimento

Enero 2021

también se convirtió en un acuerdo efímero. Estos pactos funcionaron de manera más coherente con el grupo conformado por trabajadores $\mathrm{CRE}^{7}$ a partir de un proceso de comunicación docente bidireccional.

A partir de la complejidad epidemiológica en el país se re-acordaron fechas de entrega de los trabajos, se reorganizaron la cantidad de evaluaciones con la intencionalidad de que ningún estudiante perdiera el curso, hoy 8 de febrero de 2021 sigo ajustando entregas de evaluaciones pues aun la universidad no ha podido reanudar el curso escolar de modo presencial y pese a que hace ahorita un año de nuestros primeros intercambios por el chat, seis estudiantes fueron a segunda vuelta, extraordinario por no completar el ritual de paso, o sea la evaluación.

\section{¿Descostrarme?}

Mi entrada al chat estuvo motivada por un ejercicio de poder -evaluar-,

borrosamente consensuado por las partes implicadas

Danza contemporá...
Pues me parece muy
bien reír a mandibula
batiente y saben ...
pensaba para
continuar el diálogo
con ustedes sobre el
cuerpo en lo
siguiente, cuántas
veces tratamos a
nuestros cuerpos
como sirvientes?
Ahora te toca esto o
aquello, entablamo

ello, soy como la ciega que se contempla ante el juego cultural de sus espejos, como buena carcelera pretendo reclutarlos mediante la instrucción, por ello recurro al embeleso y me construyo como una acompañante de los/las estudiantes en el proceso de enseñanza-aprendizaje, juego en el que se entrecruzaron planos mentales y conductuales

\footnotetext{
${ }^{7}$ CRE curso regular por encuentro es una modalidad en la cual los/las bailarines profesionales acceden a estudiar una vez culminadas sus labores en la compañías en horario comprendido desde la 6 pm hasta la $10 \mathrm{pm}$
} 
DOI: https://dx.doi.org/10.17561/rtc.19.6230 Investigación
La cuestión imaginativa: del dibujo y la fotografía a la imagen en movimento

Enero 2021

en el chat (Anta y Palacios 2003)

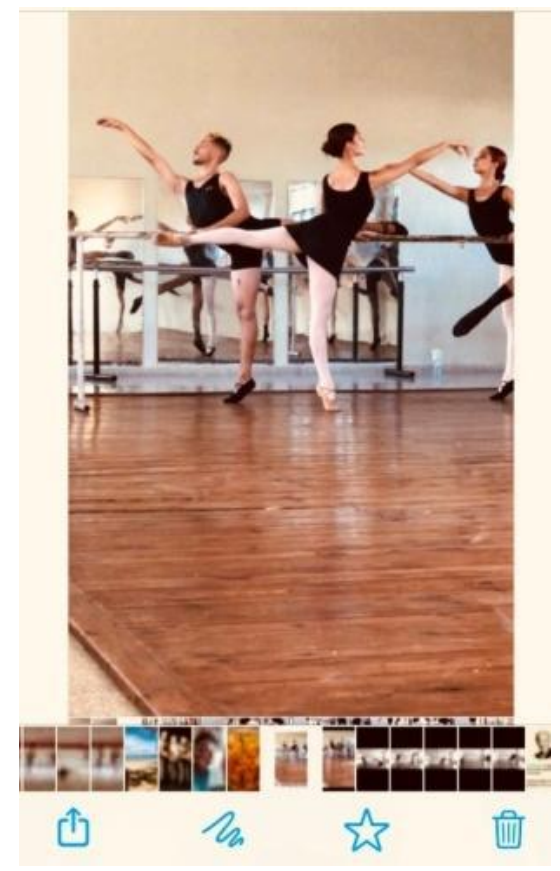

poder/subordinación; proceso/fin; estableciendo una dicotomía entre los poderes mente/cuerpo maestro/estudiante ciencia/arte, sin embargo, fuimos capaces pasados los meses de simular acompañarnos virtualmente. Como resultante se establecieron relaciones de crecimiento y aprendizaje en tanto los maestros/maestras se encargaban de

poner en el chat a disposición de los estudiantes libros,

Danza contemporá...
violencias. Los
nuevos tabúes sobre
la alimentación. El
destete etapa de alta
presión cult. La
búsqueda de la
blancura alimentaria
para sustituir la leche
materna
Consumo unisexual
de la comida.
Recuerden
Aristóteles. Los
nuevos tabúes el
azúcar y el pan.
$+\quad 0$


DOI: https://dx.doi.org/10.17561/rtc.19.6230 Investigación
La cuestión imaginativa: del dibujo y la fotografía a la imagen en movimento

Enero 2021

coreografías en este sentido fue destacable la presencia del Dr.C Bonilla

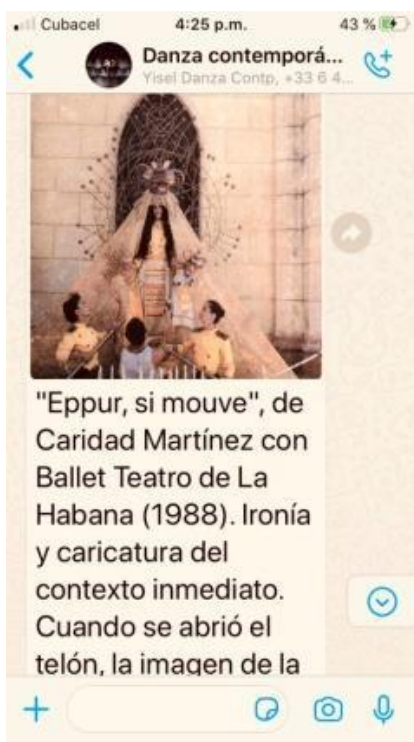
(2) (0)

Chongo

\author{
Buenas tardes, por \\ favor, recuerden que \\ mañana deben \\ enviarme el primer \\ reporte de lectura. \\ Esto es necesario \\ para orientales la \\ evaluación de la \\ próxima semana. \\ Pueden hacerlo por \\ chat privado o \\ enviarlo a
}

quien asiduamente colocaba contenidos en el chat.

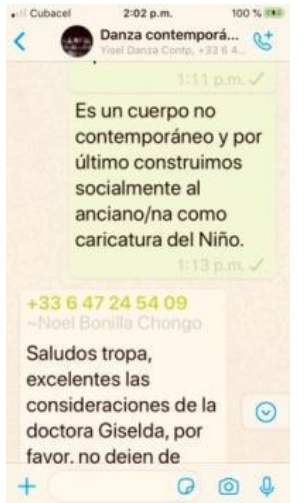

Ante el silencio sospecha de que psicológicamente no estaban receptivos a la enseñanza Wolcott, $\mathrm{H}$. hecho corroborado ante la falta de intercambio sobre los análisis de las lecturas 
DOI: https://dx.doi.org/10.17561/rtc.19.6230 Investigación
La cuestión imaginativa: del dibujo y la fotografía a la imagen en movimento

Enero 2021

orientadas por mí para dar cumplimiento al ritual de paso; reconocer esta hostilidad me hizo replantearme el asunto y me tracé una estrategia realista, comencé a enviarles análisis de las lecturas que no fueron retroalimentados, ellos y ellas

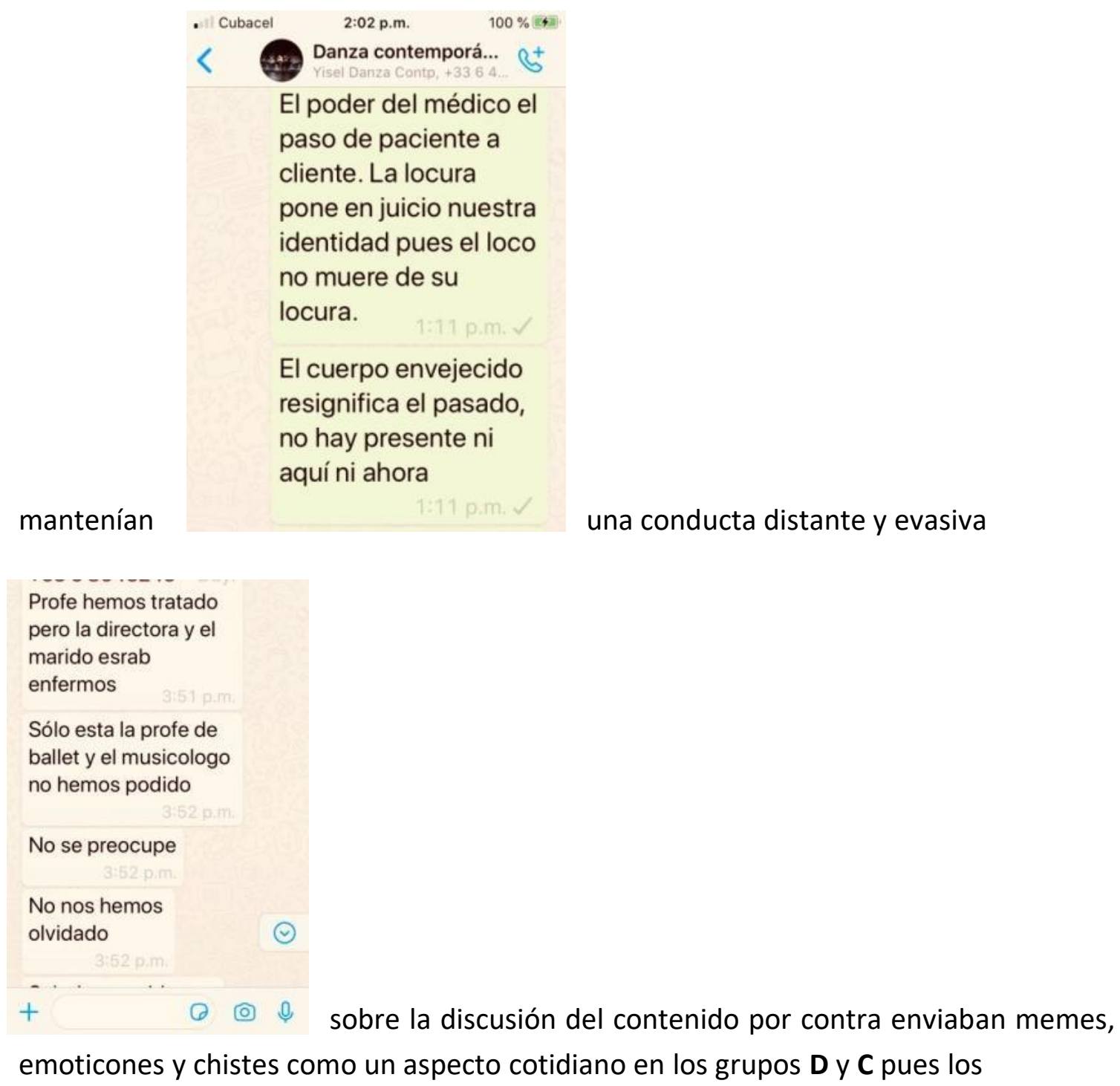


DOI: https://dx.doi.org/10.17561/rtc.19.6230 Investigación
La cuestión imaginativa: del dibujo y la fotografía a la imagen en movimento

Enero 2021

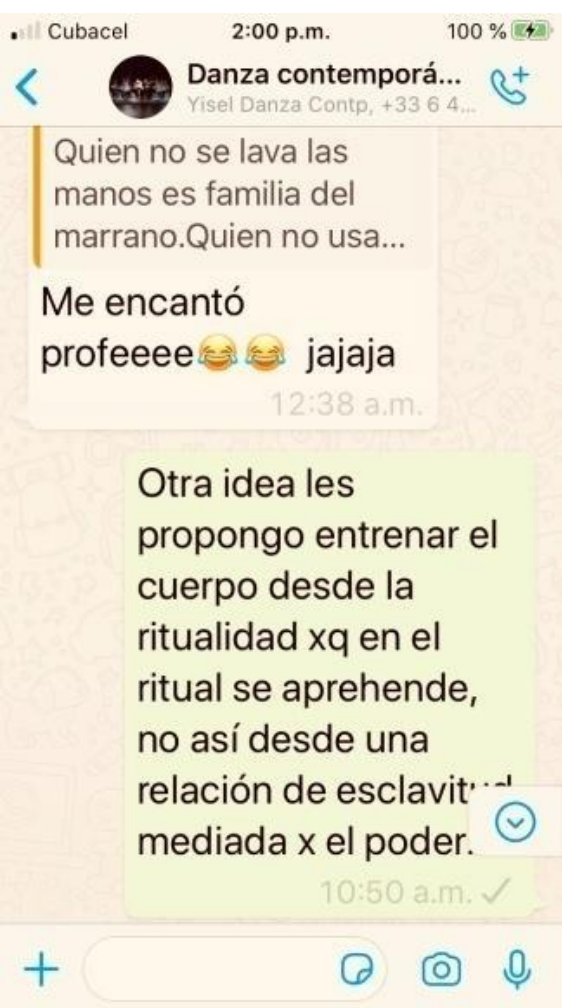

$+\quad 0$ (2)

estudiantes

del grupo $\mathbf{F}$ se mantuvieron hostiles, sin intercambiar sms, evidenciando un antagonismo dirigido al medio cultural donde nos hallamos inmersos (Wolcott, H). El silencio elocuente de este grupo, el único que obró desde la resistencia resultó muy atípico e inspirador pues los/las bailarines producto de su entrenamiento desde edades tempranas suelen normalizar la violencia en todas sus variantes, aspecto evidente en el grupo CRE, trabajadores ${ }^{8}$ con una alta receptividad psicológica ante el aprendizaje, intercambios inmediatos, colaborativos, prontitud y calidad en sus trabajos. Lo cotidiano en este chat fue el intercambio académico, no pude observar antagonismo por mantener su identidad, ni resistencia ante una situación impuesta que no fue consensuada lo que devela que al ser trabajadores de cultura en ejercicio ya han sido adocenados y reclutados. Tristemente, hoy me cuestiono lo que llamé resistencia y hostilidad del grupo $\mathbf{F}$ y que tanto me regocijó en el momento pues he constatado que su silencio obedeció a otras causas y no a demandar acuerdos.

\footnotetext{
${ }^{8}$ Las personas que nos hallamos trabajando ya hemos sido reclutadas, adocenadas, domesticadas por el sistema y robóticamente respondemos a las imposiciones de las instituciones sin siquiera sospechar de las intenciones de las mismas es por ello que cuando descubro estudiantes que pujan por sus derechos me lleno de esperanzas.
} 
DOI: https://dx.doi.org/10.17561/rtc.19.6230 Investigación
La cuestión imaginativa: del dibujo y la fotografía a la imagen en movimento

Enero 2021

La capacidad de representación en los chat

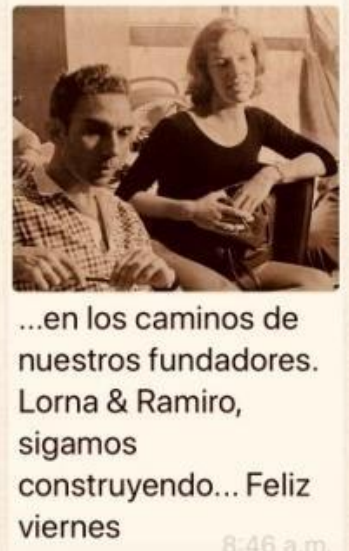

fundamentalmente estuvo centrada en el cuerpo, a través de fotos compartidas en las

que se les veían haciendo ejercicios físicos, develando

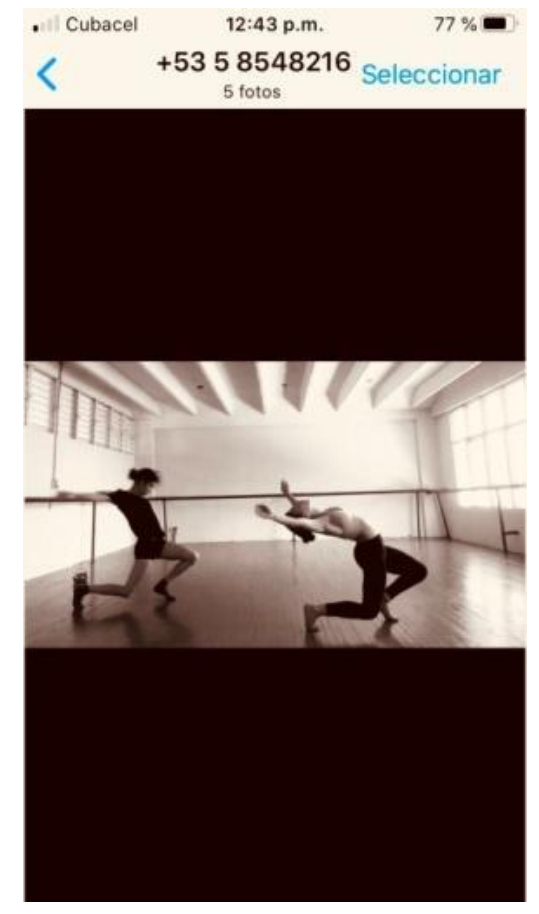

sus capacidades artísticas, orientaciones de valores y estilos de vida durante el confinamiento; fue recurrente en los cuatro grupos de WhatsApp creados la preferencia a salir del chat colectivo y recurrir a los privados para la entrega de trabajos, evidenciando una postura de autoprotección ante el error, miedo al ridículo, 
DOI: https://dx.doi.org/10.17561/rtc.19.6230 Investigación
La cuestión imaginativa: del dibujo y la fotografía a la imagen en movimento

Enero 2021

a exponerse ante los

Cubacel 12:41 p.m.
Buenas tardes profe.
Tengo el trabajo que
me falta terminado,
pero lo tuve que
hacer a mano porque
tengo la computadora
rota. No confío en el
movil para hacerlo,
por los errores que
pueda tener. En
cuanto pueda
teclearlo se lo envío.
Saludos y besitos a
todos.
土52 $52128 a n a$
$+\quad$

demás, un contrasentido si se tiene en cuenta que son bailarines que se relacionan con el público, asimismo se pudo constatar un comportamiento tendencioso a una alta competitividad y la negativa a crecer en grupos aspecto casi endémico a la formación artística pero que, en el caso de los bailarines obra como sinrazón pues generalmente ellos y ellas bailan en compañías.

Fue apreciable dentro de los simulacros culturales haber construido grupos para intercambiar conocimientos sin embargo, no se utilizaron con este propósito. Los contenidos elaborados en los chat grupales se dirigieron a la esfera de lo afectivo. Los juegos de identidad se dieron a nivel de las capacidades dancísticas, el chat en danza contemporánea por ejemplo se edificó como un espacio virtual de reconstrucción y afianzamiento de las capacidades técnicas del bailarín dicotomizadas de las intelectuales pues no se constituyeron foros de debates, este aspecto sigue apuntando a la dicotomización del cuerpo del bailarín en formación que perpetúan claves que generan y consolidan "matrices simbólicas de desigualdad" ${ }^{9}$ (Citro, S. p.31).

\footnotetext{
${ }^{9}$ Los pares cultura/naturaleza, abstracto/concreto, teórico/empírico, objetivo/subjetivo, mente/cuerpo et,alse subsumen en el modelo formativo de la enseñanza dancística y atraviesan la auto y la observación que realizamos y realizan los bailarines de sus cuerpos.
} 
DOI: https://dx.doi.org/10.17561/rtc.19.6230 Investigación
La cuestión imaginativa: del dibujo y la fotografía a la imagen en movimento

Enero 2021

Es apreciable el entrecruzamiento de planos mentales

\section{Gracias les estoy} terminando un

Powerpoint sobre Martí para ayudarlos en su estudio y preparación para cuando nos reincorporemos poder realizar con éxito el seminario

+5358811752

dy dis det dis

+ (2) ? y conductuales en el chat, por una parte, los maestros/tras que mantuvimos la "comunicación" en los grupos creados colocábamos contenidos de nuestras asignaturas y frases alentadoras, en mi caso personal busqué diversos reforzadores

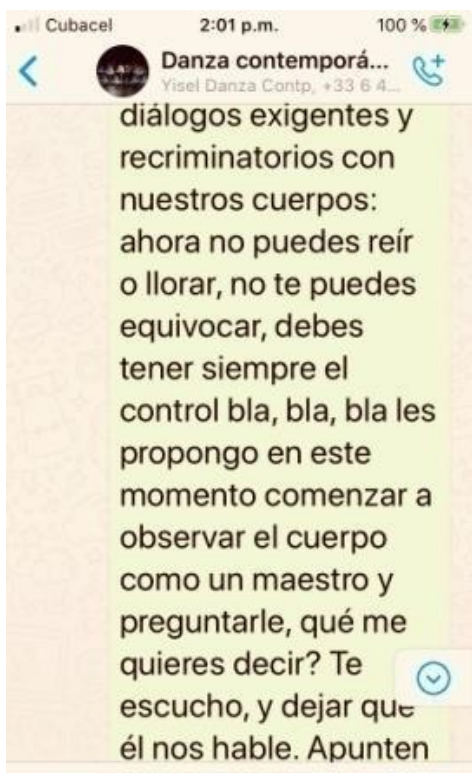


DOI: https://dx.doi.org/10.17561/rtc.19.6230 Investigación
La cuestión imaginativa: del dibujo y la fotografía a la imagen en movimento

Enero 2021

casos excepcionales, la media dirigió el dialogo hacia el humor y lo afectivo,

Danza contemporá...
nomosexualıaad, el
incesto, narcisismo. El
cuerpo como
máquina que expresa
desigualdades
La construcción de la
identidad corporal
desde la
contemplación
conferida al poder. El
espejo como
metáfora y objeto real
que permite observ
el cuerpo

este aspecto pudiera dar fe del miedo generado por la

pandemia y la incertidumbre a culminar un curso que se antojó atípico, es válido señalar que los esfuerzos institucionales se dirigieron a que pudieran seguir entrenando su cuerpo en diversas compañías del país alternando con el desarrollo de

capacidades y habilidades que ofrecen otros saberes,

en una hoja de papel todo lo que su cuerpo les diga y guárdenlo en un sobre y si por casualidad le han dado el poder a otros/ as para que devalúen sus cuerpos busquen el sobre y lean lo que les susurró su maestro. Besos y no dejen de reír esperc que me cuenten algu Giselda.

$+\quad 0$ (0)


DOI: https://dx.doi.org/10.17561/rtc.19.6230 Investigación
La cuestión imaginativa: del dibujo y la fotografía a la imagen en movimento

Enero 2021

no obstante, ellos y ellas centraron los diálogos en el entrenamiento físico de su cuerpo apegados a su zona de confort, en el grupo $\mathrm{F}$ el silencio abarcó todas las áreas,

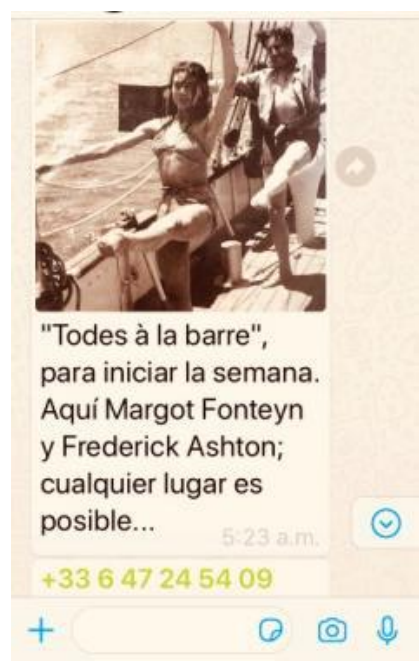

no se mostraron bailando y salvo diez estudiantes de 16 culminaron sus ejercicios académicos.

Como rasgo recurrente aparece la recreación

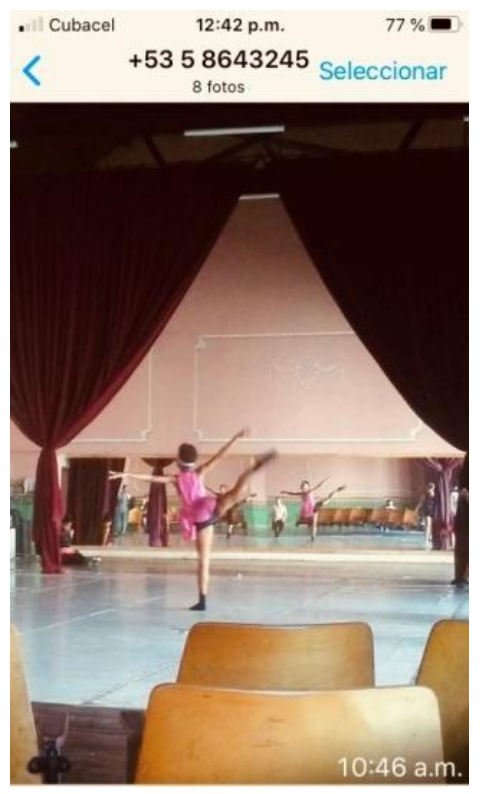

10 identitaria del cuerpo, sus capacidades y habilidades técnicas así como la resiliencia sociológica y psicológica, pues fueron capaces de generar espacios en sus casas para

10 Dayana Montalvo estudiante de danza contemporánea. 
DOI: https://dx.doi.org/10.17561/rtc.19.6230 Investigación
La cuestión imaginativa: del dibujo y la fotografía a la imagen en movimento Enero 2021

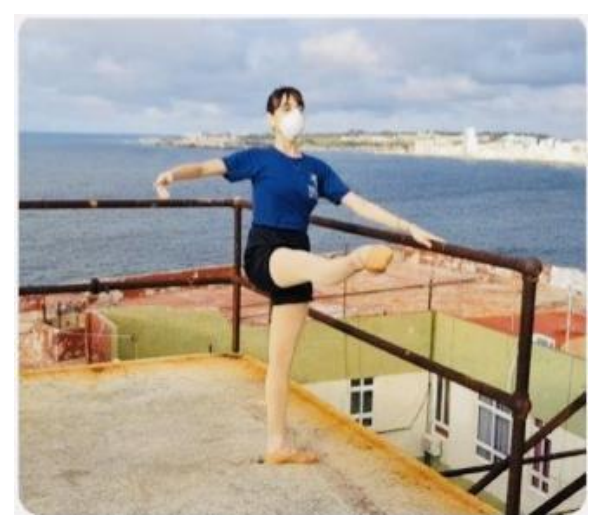

11 poder seguir entrenando. Ello dio fe de la capacidad creativa e ingeniosa de los seres humanos ante una situación adversa como la pandemia, y comportamiento típico de los humanos ante situaciones generadoras

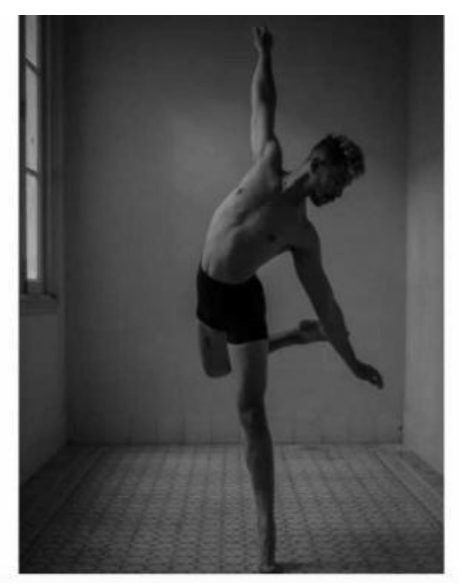

\section{Imperfecciones-}

de un alto estrés aspecto que no se pudo constatar en el grupo $\mathbf{F}$.

El doble simulacro del que participamos se caracterizó por: el juego de los espejos y simulación de conectividad, democratización del proceso de enseñanza/aprendizaje en el chat en tanto todos/todas ejecutábamos ejercicios de

\footnotetext{
11 Tomado de Viqueira, M. 2021 ensayo visual Mi cuerpo confinado.
}

12 Jorge Carlos Santana estudiante de danza contemporánea. 
poder en cuerpos construidos culturalmente desde la dicotomización. La cotidianidad de los grupos se caracterizó por aspectos muy demarcados entre los estudiantes del curso regular diurno con una tendencia a segregar el contenido de la asignatura y reforzar imágenes sobre su entrenamiento, así como la construcción de techos de cristal, por contra los trabajadores -bailarines profesionales- se centraron con mayor prontitud y receptividad en las actividades evaluativas que debían realizar y que da fe de su adocenamiento cultural.

Como aspecto recurrente aparece en los grupos del curso regular diurno durante las negociaciones para ser evaluados una tendencia a observar los conocimientos que aportan las disciplinas de formación general como meras asignaturas que deben evaluar para obtener una nota, pasar el examen sin correr riesgos, la tendencia a evaluarse por caminos trillados y una negativa casi ontogénica a emanciparse aquí me asalta la pregunta de Adorno, T. ¿a dónde debe llevar la educación? p.93, mi ¿para qué? se diluyó en mis monólogos y me indicó que aún cuando enseño para ponernos en situación del logro de la emancipación dicotómica mente/cuerpo hay una lógica de inversión que aparece cuando se trabaja con bailarines y mi objetivo se diluye en conceptos inteligibles.

No obstante, considero como ganancia que cada grupo creado se fundió/distinguió del otro, en esa suerte de metáfora social unidad " $y$ " " $y$ " diversidad en sus relacionalidades con respecto al contenido generado en el chat de valor simbólico y criterios de distinción Bourdieu, 1999, Anta y Palacios 2003 p.89; excepto los estudiantes del grupo $\mathrm{F}-$ que en su mayoría se mantuvieron sin entrar al grupo de chat auto-segregándose-, todos/todas fuimos afectivos, empáticos, colaborativos o al menos jugamos a serlo. 

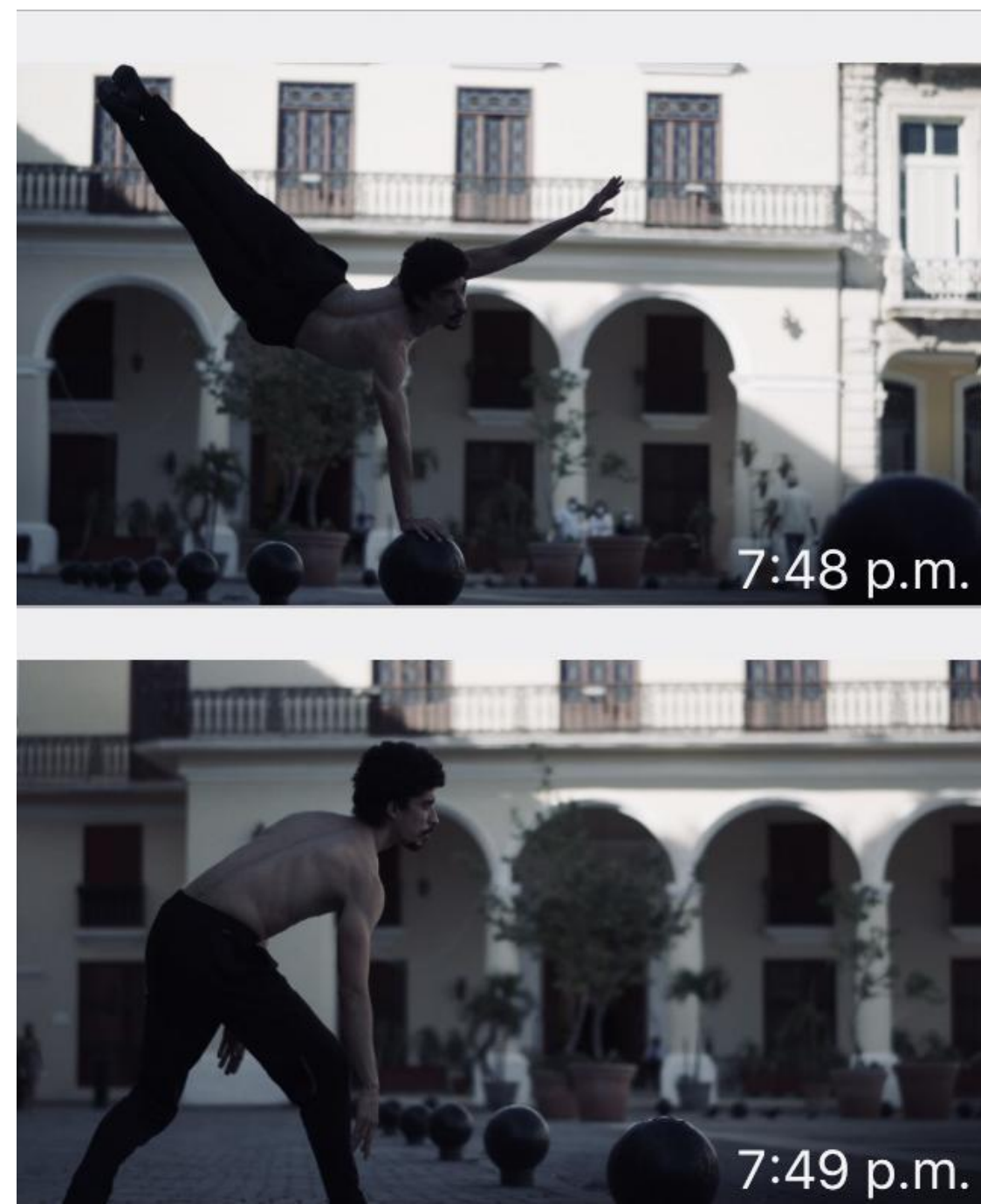

Fig. 1. Bailarín Raúl Montero: Fotos Daniel Contreras.

\section{Referencias}

Adorno, T.W.(1998). Educación para la emancipación. Conferencias y conversaciones con Hellmut Becker (1959-1969). Edición de Gerd Kadelbach: Morata, SL. Madrid. Traducción de Jacobo Muñoz. http://www.edmorata.es

Anta, J. L. y Palacios, J. (2003). Epistemología más acá de las redes. Conceptos para una Antropología Social de la modernidad: Meta 4. España. 
Benkler, Y. (2000). From Consumer to Users: Shifting the Deeper Structure of Regulation Toward Sustainable Commns and User Access. Federal Communications Law Journal(3): 561-579

Citro, S. (coordinadora) (2010). Cuerpos Plurales. Antropología de y desde los cuerpos: Biblos Culturalia. Buenos Aires.

DeNardis, L. (2010). The Emerging Field of Internet Governance. Social Science Research Network.

https://doi.org/10.2139/ssrn.1678343

Jackson, M. (2010). Conocimiento del cuerpo p.59-82 en Citro, S. (coordinadora) (2010). Cuerpos Plurales. Antropología de y desde los cuerpos: Biblos Culturalia. Buenos Aires.

Klein, H. (2004). "ICANN and Non-Territorial Souvereignty: Government Without the Nation State". Internet and Public Policy Project. Georgia Institute of Technology.

Kurbalija, J. (2014). Introduction to Internet Governance. Diplo Foundation.

Montero, R. (2021). Mi cuerpo confinado. Ensayo visual. Trabajo de clases.

Wolcott, H. (2017). El maestro como enemigo. Pp243-257 en Lecturas de Antropología para Educadores. El ámbito de la Antropología de la educación y de la etnografía escolar. (2017) Editores Velasco, H., García, J. y Díaz de Rada, A.: Trotta. Madrid.

Viqueira, M. (2021). Mi cuerpo confinado. Ensayo visual. Trabajo de clases. 